This is an Author's Accepted Manuscript of an article published by Springer in Culture, Medicine and Psychiatry on 6 November 2014. The final publication is available at Springer via http://dx.doi.org/10.1007/s11013-014-9416-5

\title{
Thwarting the Diseased Will: Ulysses Contracts, the Self and Addiction
}

\author{
Kirsten Bell \\ Department of Anthropology \\ University of British Columbia \\ 6303 NW Marine Dr \\ Vancouver, BC V6T 1Z1 \\ Canada \\ Email: kibell@mail.ubc.ca \\ Category: Original Research Article
}

\begin{abstract}
Ulysses contracts are a particular type of advance directive that has been advocated for use in mental health settings and addictions treatment. Taking their name from the legend of Ulysses, such contracts are distinctive in so far as they are designed to thwart certain anticipated future wishes rather than realize them. In this paper, I consider what Ulysses contracts reveal about contemporary conceptions of addiction and the self.

Drawing on discussions of Ulysses contracts in the psychiatric and addictions literature, as well as historical and contemporary examples of such, I show that Ulysses contracts are premised on a split between the present 'rational' self and the future 'irrational' self, thereby reproducing a very particular notion of addiction - one that serves to naturalize certain ways of thinking about freedom, choice, coercion and the self.
\end{abstract}

Keywords: Ulysses contracts - advance directives - rationality - the self addiction

Statement regarding originality: This manuscript represents original scholarship and is not currently under consideration for publication elsewhere.

\section{Acknowledgements}

I am indebted to Daniel Buchman - the person who stimulated my interest in the topic of Ulysses contracts. This article began life as a conference paper developed for the "New Social Studies of Addiction" session at the Interdisciplinary Social Sciences Conference held in June 2014 in Vancouver, Canada. I am grateful to Suzanne Fraser for the invitation to take part in the session because I doubt that I would have ever got around to writing this paper otherwise. Daniel and Amy Salmon both provided invaluable feedback prior to submission, and the two $C M P$ reviewers also encouraged me to develop certain lines of argument. 


\section{Introduction}

Ulysses contracts are a particular type of advance directive that has been advocated for use in mental health settings and, more recently, addictions treatment. They take their name from Homer's The Odyssey (see figure 1), in which Ulysses resisted the seductive but lethal call of the Sirens by ordering his crew to stuff wax in their ears and adhere to the following instructions: "Therefore, take me and bind me to the crosspiece half way up the mast; bind me as I stand upright, with a bond so fast that I cannot possibly break away, and lash the rope's ends to the mast itself. If I beg and pray you to set me free, then bind me more tightly still" (Homer 2005, p. 369). In essence, Ulysses contracts instruct others to force one to do or refrain from doing something regardless of one's anticipated resistance (Macklin 1987; Andreou 2008). Although they share certain similarities with advance care plans made in the event of future physical or cognitive incapacity (e.g., 'do not resuscitate' orders and advance directives for people with earlystage dementia), a key difference is that Ulysses contracts are designed to thwart certain anticipated future wishes rather than realize them (Andreou 2008). Moreover, at the time of the future event being planned for, the individual will likely be legally competent (or, at most, only temporarily impaired) as opposed to permanently incapacitated.

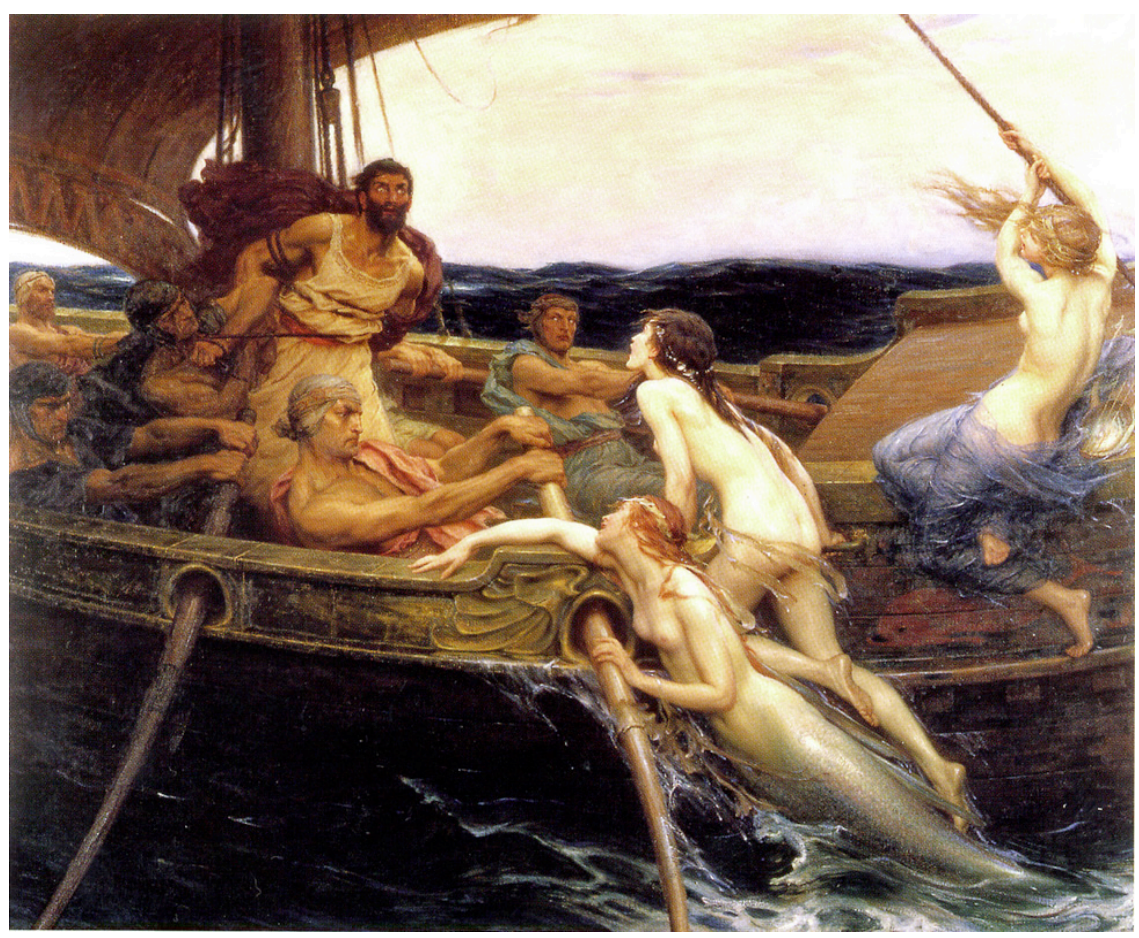

Figure 1. Ulysses and the Sirens by Herbert James Draper (No copyright restrictions)

Although proposals to give such contracts legal sanction are a relatively recent development, according to Rebecca Dresser (1984, p. 13), "we all engage in forms of self-binding. We purchase items on credit, promising to pay for them in the future. We vow to lose ten pounds or give up cigarette smoking, promising family members or friends that we will pay some penalty if we fail to attain our goals". For example, the 
notes of Thomas De Quincey's (1876) Confessions of an English Opium Eater describe the efforts of his contemporary, Samuel Taylor Coleridge, to overcome his "vassalage to opium" (p. 607) through precisely this type of self-binding. According to De Quincey, Coleridge hired porters for the express purpose of barring his entrance to any drug store in order to procure opium, which would lead to the following rather extraordinary scenes:

'Oh, sir,' would plead the suppliant porter - suppliant, yet semi-imperative (for equally if he did, and if he did not, show fight, the poor man's daily $5 \mathrm{~s}$. seemed endangered) - 'really you must not; consider, sir, your wife, and-

Transcendental Philosopher:.' 'Wife! what wife? I have no wife'.

Porter: 'But, really now, you must not, sir. Didn't you say no longer ago than yesterday-'

Transcend. Philos.: 'Pooh, pooh! Yesterday is a long time ago. Are you aware, my man, that people are known to have dropped down dead from timely want of opium?'

Porter: 'Ay, but you tell't me not to hearken-'

Transcend. Philos.: 'Oh, nonsense. An emergency, a shocking emergency, has arisen - quite unlooked for. No matter what I told you in times long past. That which I now tell you, is - that, if you don't remove that arm of yours from the doorway of this most respectable druggist, I shall have a good ground of action against you for assault and battery (De Quincey 1876, p. 606-607, emphasis in original).

As De Quincey observes, the porter was placed in an excruciating metaphysical fix because his authority for preventing entry to the drug store derived only from Coleridge himself, who would immediately revoke it when he found himself in withdrawal. The porter's quandary therefore regarded which set of instructions to prioritize: the ones where Coleridge told him to forcibly stop his procurement of opium, or those where he insisted the prior order be overridden.

Although the use of formal Ulysses contracts in psychiatric and addictions treatment is not particularly common, in this paper I am interested in exploring these contracts and the discussion they have generated as a lens into the self and addiction as 'cultural artifacts' (Stein 1990, p. 987). In other words, my goal is to locate Ulysses contracts within their particular cultural milieu, which I suggest is crucial to understanding why they have emerged as a potential solution to the 'problem' of addiction and the perceived threats it poses to the self. In aid of this agenda, I explore the initial appearance of this concept in the psychiatric and additions literature, along with the subsequent debates it engendered.

\footnotetext{
${ }^{1}$ This is the rather mocking term De Quincey uses for Coleridge. Although initially friends, relations soured over time and De Quincey seems to have delighted in portraying Coleridge in a less-than-ideal light in various essays, from his Confessions of an English Opium Eater to Lake Reminiscences (fuelled in part by his obvious anger at what he perceived as Coleridge's unflattering characterizations of him).
} 
Drawing on examples from popular culture, I aim to show that Ulysses contracts rely on - and reproduce - a very particular notion of addiction, one that serves to naturalize certain ways of thinking about freedom, choice, coercion and the self.

\section{Ulysses contracts and the psychiatric literature}

It is difficult to pinpoint who initially raised the topic of Ulysses contracts in the psychiatric literature, because several people appear to have independently converged on the idea in the early 1980s. The first reference to the concept occurred in a paper on the morality of involuntary hospitalization (Culver and Gert 1981). In discussing the problem of "recurrent manic attacks" (p. 171), Culver and Gert observed that some patients were themselves apprehensive about the harm they might do if and when future manic episodes occurred. They raised the question of whether such patients could appoint a proxy or guardianship committee that could sanction future detention and treatment decisions. In their words, "this might be called an Odysseus Pact or Odysseus Transfer and be thought of as a psychiatric analogue of the 'living will"' (p. 171). Shortly afterwards, Howell et al. (1982) published an article endorsing such "binding voluntary commitment", outlining the situations in which such contracts might be implemented and the form they might take. They argued that Ulysses contracts might appear paternalistic but that such views were themselves the product of paternalism. In their words,

Given the nature of their predicament, these patients might argue that to refuse them the opportunity and resources to make such arrangements to protect themselves and others from their psychotic behavior would itself be an unwarranted, paternalistic infringement on their liberties (p. 167)

The following year, Winston and Winston (1982) independently raised the notion of the Ulysses contract in a discussion of the participation of a schizophrenic man, 'J.S.', in a medical study. Although J.S.'s schizophrenia was controlled via anti-psychotic medication, he had developed an irreversible iatrogenic condition called tardive dyskinesia as consequence of the anti-psychotic drugs. An experimental treatment for the condition became available and J.S. was accepted into the study, which required him to sign a variety of consent forms. He was then taken off his meds, including his antipsychotics, wherein he immediately regressed to an acutely psychotic state and refused the experimental medication. Although the researchers wanted to continue with the treatment based on J.S.'s initial consent during his "competent hours", the treatment unit's lawyer advised against it and J.S. was taken off the study and placed back on antipsychotics. When he returned to 'normal' and learned what had happened, he begged for another chance to re-enroll. Winston and Winston suggested that such dilemmas could be resolved "If there were a regular procedure for drawing up Ulysses contracts, allowing patients to specify in advance the precise conditions under which their requests or protests are to be disregarded, and to designate someone to act as their proxy under those conditions" (p. 27).

A third iteration of the Ulysses contract was outlined in a 1982 paper by Thomas Szaszalthough he did not use the term, instead preferring the phrase "psychiatric will". It is worth highlighting Szasz's particular contribution because he is psychiatry's foremost 
critic, especially regarding the forced institutionalization of people deemed mentally illa category he rejected as a "metaphor and a myth" (Szasz 1982, p. 762; see also Szasz 1970, 1973). Szasz envisioned the psychiatric will as a way to provide "complete protection from coerced psychiatry without depriving persons who wish to be the beneficiaries of involuntary psychiatric interventions from the protections that such measures allegedly offer" (p. 762). Much like a living will, it would provide a means of outlining what kinds of treatment were and were not acceptable to individuals in the event of future designated mental incapacity. Thus, for Szasz, the psychiatric will asserted: "In effect, that competent American adults should have a recognized right to reject involuntary psychiatric interventions that they may be deemed to require in the future, when they are not competent to make decisions concerning their own welfare" ( $\mathrm{p}$. 766 , emphasis in original).

As should be evident, the perceived function of the Ulysses contract differed significantly in these accounts and reflected the varied epistemological commitments of their authors.

In two articles they were endorsed as a means of preemptively agreeing to treatment, ${ }^{2}$ and in the third they were promoted primarily as a means of preventing it. However, the former version of the Ulysses contract soon came to dominate the literature. ${ }^{3}$ As patients' rights advocates have observed, there is often no implication that the Ulysses contract "might include a list of acceptable and unacceptable alternatives among treatment choices" (Rogers and Centifanti 1991, p. 11, emphasis added). Despite (or perhaps because of) its narrow focus, the notion of the Ulysses contract quickly caught the imagination of psychiatrists and ethicists, and support was expressed in numerous quarters. However, several legal scholars challenged the feasibility, legality and ethical implications of such contracts.

Dresser (1984) pointed out that if the person about to be forcibly confined or treated according to the terms of the initial Ulysses contract challenged the coercion, the court would be required to adjudicate the case. State intervention on a regular basis was thus inevitable, "since it is assumed that the person's condition would cause him/her to resist such intervention" (Macklin 1987: 40). But because of the uncertainty inherent in psychiatric diagnosis and prediction, and the complexity, inconsistency and spontaneity of human behavior and decision-making, the court would then enter murky legal waters.

\footnotetext{
2 Although in Winston and Winston's account, the treatment pre-emptively agreed to was an experimental one for an iatrogenic consequence of psychiatric treatment itself. Somewhat ironically, the Ulysses contracts they advocate would only exacerbate these kinds of iatrogenic consequences, because people's disinclination to continue using medications causing such effects would be automatically overridden on the basis of their prior consent. This is one (among many) of the reasons why such contracts have failed to gain a legal foothold.

${ }^{3}$ Because of this tendency, some commentators distinguish between 'psychiatric wills' and 'Ulysses contracts', with the former perceived as providing a blanket 'no' to future coerced treatment and the latter providing a blanket 'yes' (see Macklin 1987). However, it is clear that Szasz (1982) perceived the psychiatric will to cover both possibilities. To make things even more confusing, Rosenson and Kasten (1991) introduce a third option which they label the 'Mill's will' (after John Stuart Mill) that would outline both acceptable and unacceptable treatment options.
} 
Thus, Dresser concluded:

The suffering of individuals with recurrent mental disorders deserves our concern and attention. But by adopting a program in which the government becomes Ulysses' crew, restraining unwilling individuals to protect them from harm that, unlike the Sirens' song, does not endanger life and might well fail to materialize, we risk embracing a solution with higher costs than the problem it attacks (p. 16).

Although not opposed to such contracts in principle, the legal scholars Nancy Rhoden (1982) and Audrey Macklin (1987) similarly highlighted their legal complexities. Both pointed to the ethical problems that arise with making initial consent absolutely binding, which would seem to be a necessary precondition of a Ulysses contract (as Coleridge's unsuccessful Ulysses contract with his porter suggests). Emphasizing the need for thirdparty involvement to ensure that patients could opt out of Ulysses contracts under certain circumstances, Rhoden (1982, p. 28) suggested that physicians could give patients the option of "appointing... a relative, friend, attorney, or other individual... who could act as a substitute decision maker in the event the patient again lapses into incompetency". Likewise, for Macklin (1987, p. 40): "An interested third party, such as a friend or lawyer, should also be involved to ensure that the best interests of the individual are served" (Macklin 1987: 40).

As these accounts make clear, despite the emphasis on the ways in which Ulysses contracts preserve the patient's autonomy, they fundamentally rely on a second or third party to enforce them, placing such persons (or institutions) in the unenviable role of carrying out the person's prior wishes in the face of their present recalcitrance. As Chodoff and Peele (1982, p. 12) observed in their critique of Szasz's 'psychiatric will' proposal, "The consequences of a living will will be felt principally by the person who signs it. The psychiatric will is much more likely to affect others around the signer". They raised questions about the potential for litigation against the party tasked with carrying out the contract; indeed, such parties could potentially be liable for whichever path they take - action or inaction. For these reasons, while calls have been periodically made to revisit Ulysses contracts (e.g., Rosenson and Casten 1991; Spellecy 2003; Davis 2008; Walker 2012), and twelve US states have taken steps to implement laws regarding them under the rubric of the 'advance psychiatric directive', their legal status remains murky (see National Alliance on Mental Illness 2014).

\section{Ulysses contracts expand to addictions treatment}

It is unclear when the possibility of implementing Ulysses contracts in the treatment of addiction was initially raised. However, support was expressed from several disparate quarters. Somewhat unexpectedly, the earliest scholars to discuss the utility of Ulysses contracts in combating addiction were proponents of rational choice theory. Rational choice theory is the broad term for a collection of approaches that coalesced from the 1950s with roots in neoclassical economic theory, utilitarian theory and game theory (Green and Shapiro 1994; Zey 1998). At its core lies the idea that individuals act as if balancing costs against benefits to arrive at an action that maximizes personal interest or 
utility (Green and Shapiro 1994; Zey 1998). Central to its organizing logic is the assumption that "the individual is purposive and intentional; that is, actors have ends or goals toward which their actions are aimed" (Zey 1998: 2). Rational choice theorists recognize that there are certain constraints on rational action; however, they assume that individuals choose what they believe to be the best means to achieve their given ends (although they may not actually be such). Although its influence is most heavily felt in economics and political science, the core assumptions underpinning rational choice theory have touched a variety of fields.

That proponents of rational choice theory would be interested in addiction is at first glance surprising. After all, addiction is generally perceived to be harmful to the person who experiences it and many so-called 'addicts' express the desire to change their behavior but are unable to do so (Herrnstein and Prelec 1992). As Herrnstein and Prelec (1992) observe, attempts to reconcile addiction with rational choice models of human behavior have taken several forms. Some argue that addiction is a disease, and, as such, is an attribute the individual has no control over, thereby nullifying the need to explain the 'addict's' apparent departures from the basic tenets of rational choice models. Others suggest that addiction is a form of self-medication: a rational response to psychological ailments or impoverished social conditions. Such ideas clearly inform mainstream harm reduction discourses, which are founded upon a particular conceptualization of the sovereign individual centered on ideals of autonomy and rationality (Keane 2003; O'Malley and Valverde 2004; Moore and Fraser 2006). They take some of their impetus from Bruce Alexander's famous 'Rat Park' experiments, in which caged, isolated rats self-administered high doses of opiates, whereas those in 'Rat Park' - a comfortable, spacious enclosure where rats were able to cohabitate and live 'naturally'-generally chose to forego opiate-laced water in favor of plain $\mathrm{H}_{2} \mathrm{O}$ (Pickard and Pearce 2013). A third view - and the one of most interest for my present purposes - is based on the assumption that the same person has different preferences at different points in time, a phenomenon that rational choice theorists have labeled "intertemporal inconsistency", (Herrnstein and Prelec 1992, p. 354). This concept serves to explain much of the interest in Ulysses contracts amongst rational choice theorists.

In his book Ulysses and the Sirens, the philosopher Jon Elster ${ }^{5}$ (1984) argues that humans exhibit an imperfect rationality: we know what choices we should make but often fail to make them. He argues that Ulysses' response to the Sirens illustrates this aspect of our psychological makeup because a fully rational being would not have needed to resort to self-binding in the first place; he would simply have placed wax in his ears to avoid the temptation of the Sirens' song entirely. Elster suggests that because of our imperfect rationality, which is primarily the consequence of a weakness of will, precommitment behavior provides an important means of "achieving rationality by indirect means" ( $p$. 37). For example, he observes that in quitting smoking, it is "standard practice to set up

\footnotetext{
${ }^{4}$ Although it takes some of its impetus from the philosopher Harry Frankfurt's (1971) earlier work on first and second order desires.

${ }^{5}$ Elster (2007) has more recently critiqued the explanatory power of rational choice theory.
} 
some causal machinery that will add force to your inner resolution" (p. 37). Evidencing some awareness of the literature on Ulysses contracts in mental health settings, he also points to the use of advance directives for people with recurrent mental illness, noting that the Norwegian 'Law of psychic health protection' enables a person to voluntarily seek irreversible admission to a mental hospital.

The use of Ulysses contracts in addictions treatment was later elaborated on by the economist Thomas Schelling (1992) in a chapter in a book on temporality and choice. In his discussion of self-command strategies, Schelling describes a cocaine addiction treatment centre in Denver that gave patients the opportunity to write a self-incriminating letter, preferably one confessing their drug addiction, which they deposited with the clinic. In the event that they failed a random drug test, the clinic would send the confessional letter to the designated addressee. The example Schelling provides is of a physician who addresses a letter to the State Board of Medical Examiners confessing that he has administered cocaine to himself and requesting that his license to practice be revoked. In Schelling's words, "Faced with the prospect of losing career, livelihood, and social standing, the physician has a powerful incentive to stay clean" (p. 167).

Although Schelling characterizes such actions as "self-blackmail in one's own long-term interest" (p. 169), he does make reference to the story of Ulysses and the Sirens.

Seemingly unaware of the intensive discussion of Ulysses contracts in the psychiatric literature, he argues that such strategies provide a potentially powerful means of selfmanagement to command and constrain future behavior. In his words:

The problem is to make oneself behave as one has resolved to behave, especially in moments of crisis or whenever the resolve may lapse, and the tactic is to structure incentives so that even if the original motivation for behaving as resolved should fade or be rationalized away, there remains a forbidding consequence of misbehavior to provide the necessary discipline (Schelling 1992: 167).

Elster (2000) expanded on these ideas in his book Ulysses Unbound: Studies in Rationality, Precommitment and Constraints. Discussing "addictive behavior" as "the most striking instance known to me of ambivalence or weakness of will" (p. 63), he continues, "Many addicts really, strongly want to quit; try again and again; fail again and again; succeed and then relapse; try again, and then relapse again" (p. 63). Elster argues that pre-commitment behavior provides a valuable technique for overcoming addiction because it does not rely merely on willpower but on external constraints that serve to limit individual choices.

Although rational choice theorists focused primarily on personal strategies for selfcontrol rather than formal precommitment mechanisms that would bind people to treatment, the possibility of utilizing Ulysses contracts for these purposes has been more recently raised in the addictions literature. For example, in 2004, a group of Dutch psychiatrists discussing the ethics of forced treatment for addiction (Janssens et al. 2004) argued that the contemporary emphasis on patients' rights to non-intervention has led to 
their abandonment in the name of autonomy. Endorsing conditional court orders enforcing treatment, they also discuss the possibility of patient-initiated court orders that essentially regulate the patient's continuing treatment, even if the patient later wants to withdraw, or that permit involuntary treatment in the event that the patient starts using drugs again. While they do not use the term 'Ulysses contract' to refer to these court orders, they do cite several papers from the psychiatric literature on this topic. In their view, "it can be argued that this option does not harm the patient's autonomy... The patient allows his longer term goals and values to prevail over his short term desires" ( $p$. 457).

A 2008 paper by a bioethicist similarly suggests that such contracts ${ }^{6}$ might feasibly be implemented in the context of addictions treatment. Drawing on various postulated models of addiction, Chrisoula Andreou (2008) argues that the use of Ulysses contracts would be ethically warranted in certain contexts. For example, discussing the 'irresistible cravings' model, she highlights the ways in which some 'addicts' are subject to cravings that compel them to act against their considered preferences. Similarly, invoking the 'preference reversals' model, she argues that in some instances they abandon longstanding resolutions when the opportunity for indulgence is imminent but cling to resolutions to exercise restraint in the future. Thus, "enforcing a Ulysses contract need not involve arbitrarily respecting the preferences of a past self over the preferences of a current self, or assuming that the agent's past preferences are more authentic or sound than her current preferences" (p. 27). She concludes that in some situations involving addiction, Ulysses contracts are both useful and legitimately enforceable and suggests that further research on their uses in addictions treatment is necessary.

\section{Conceptions of the self in Ulysses contracts}

As should hopefully be evident, discussions of Ulysses contracts in the psychiatric and addictions literature are fundamentally concerned with questions of individual autonomy and the nature of the self, and draw on very particular conceptualizations of both (Dresser 1984; Radden 1988). In virtually all accounts of the Ulysses contract, a notion of dual or divided selves is evoked. ${ }^{7}$ In the words of Audrey Macklin (1987):

Binding oneself, or self-paternalism, essentially postulates two selves: the 'true' self that wants to quit smoking, lose weight, or remain in control of its mental processes, and the 'other' self that smokes too much, eats too much, or behaves self destructively. A Ulysses contract allows the healthy self to paternalize the sick self by binding the latter to commitment and treatment because of and despite anticipated resistance. The earlier self perceives the act of contract formation as

\footnotetext{
${ }^{6}$ Andreou indicates that she is considering only informal rather than legally binding Ulysses contracts. This becomes a way of endorsing them without tackling the fact that those Andreou envisions as being "charged with enforcing the Ulysses contract" (p. 31) would only be able to do so with some legal backing, an issue she dismisses by stating that "the agent should thus acknowledge the legitimacy of interference based on his directive" (p. 31).

${ }^{7}$ The key exception is obviously Szasz (1982), who explicitly rejected the assumptions on which most versions of the Ulysses contract were based, proposing it as a means of protecting patients from psychiatrists (rather than themselves).
} 
autonomous; the later self perceives enforcement as paternalistic. The source of the paradox, of course, is that patemalizer and paternalized inhabit the same body (p. 48).

The debates about Ulysses contracts have thus centered primarily on the question of what constitutes the individual's 'authentic', 'real', 'true' self, and how to ascertain its 'wishes', 'desires', and 'preferences'. Proponents argue that such contracts actively promote this autonomous and authentic self, whereas a small group of critics (e.g., Dresser 1984; Radden 1988) see them as potentially undermining it. What is not under debate in these discussions are the concepts of 'autonomy' and the 'self' themselves.

As Seear and Fraser (2010: 440) observe, late modernity is marked by a cultural valorization of agency, rationality, autonomy and choice. Thus, the 'self' enacted in these accounts is a very particular historical and cultural product. According to Nikolas Rose (1998), the 'invention' of the self is connected with the rise of the 'psy' sciences from the mid-nineteenth century, which took the self as their key object but simultaneously constituted it in the process of knowing it. In his words,

The self is to be a subjective being, it is to aspire to autonomy, it is to strive for personal fulfillment in its earthly life, it is to interpret its reality and destiny as a matter of individual responsibility, it is to find meaning in existence by shaping its life through acts of choice. These ways of thinking about humans as selves, and these ways of judging them, are linked to certain ways of acting upon such selves (p. 151, emphasis added).

As we have seen, the Ulysses contract simultaneously relies on this notion of the self and seeks to recover it.

Drawing heavily on Foucault, Rose (1998) argues that this "autonomization of the self" is a central feature of contemporary governmentality insofar as the autonomy of the self is not the antithesis of political power, but one of its objectives, instruments and strategies. Rose particularly highlights the rise of "enterprise culture" in the 1980s and the ways political rhetoric and regulatory programs were linked to the "self-steering" capacities of individuals themselves (p. 154). As he elsewhere observes, "the beauty of empowerment is that it appears to reject the logics of patronizing dependency that infused earlier welfare modes of expertise. Subjects are to do work on themselves, not in the name of conformity, but to make them free" (Rose 2000, p. 334).

In many respects, the Ulysses contract is the product of this logic, whereby the self is envisioned as a 'project' to be continually worked upon and improved (or reclaimed, as the case may be). As Jennifer Radden (1988, p. 88) notes, in this framing a particular version of autonomy is prioritized - one whose outcome is a "fuller and more productive life". Thus, people with mental health disorders (now discursively transformed into 'mental health consumers') speak of such contracts as helping them exercise their "right to plan in an intelligent, self actualizing manner" (Rogers and Centifanti 1991, p. 11) and mental health specialists describe them as empowering patients to take a "proactive 
stance" towards their illness and facilitating "autonomy based on enlightened selfinterest" (Rosenson and Kasten 1991, p. 2, 5). The healthcare saving such contracts generate also features prominently in some accounts (e.g., Rosenson and Kasten 1991; Cuca 1992). For example, Roberto Cuca (1992, p. 1152) notes:

Many patients with recurrent mental illnesses experience periods of lucidity alternating with relapses into incompetence. For some, the mental illness manifests itself in part through the refusal of all treatment offers and a denial of the disease. As a result, these patients must undergo an often lengthy commitment process before their physicians can administer medication that may return them to lucidity. The hearing process and attendant hospitalization can be very costly for the patient, the patient's family, and the state.

However, this view of the self also resonates with older ideas about the relationship between the state and the individual, especially as articulated in the work of the chief architect of liberal political philosophy, John Stuart Mill. In his essay titled On Liberty, Mill (1859) explored the relationship between liberty and authority, focusing particularly on the nature and limits of the power that society can legitimately exercise over the individual. Mill asserted that it was only possible to exert compulsion and control over another - either by legal penalties or moral coercion — when an individual's actions could harm others. In Mill's words:

The only part of the conduct of any one, for which he is amenable to society, is that which concerns others. In the part which merely concerns himself, his independence is, of right, absolute. Over himself, over his own body and mind, the individual is sovereign (Mill 1859, p. 13).

This emphasis on sovereignty is critical to Mill's moral philosophy and has strongly influenced contemporary conceptions of 'autonomy', 8 which is today enshrined at the heart of our medical and legal systems. According to one influential definition:

Personal autonomy is, at minimum, self-rule that is free from both controlling interference by others and from limitations, such as inadequate understanding, that prevent meaningful choice. The autonomous individual acts freely in accordance with a self-chosen plan analogous to the way an independent government manages its territories and sets its policies (Beauchamp and Childress 2001, 58).

This political analogy suggests that the legitimacy of self-rule relies on particular capacities and attributes. In certain contexts, they may be seen to be entirely absent-

\footnotetext{
${ }^{8}$ I should emphasize that Mill himself did not use the term autonomy. His interest was specifically in the nature of (and limits to) individual liberty. However, contemporary notions of autonomy have been unquestionably influenced by his ideas, along with Emmanuel Kant's work on moral autonomy.
} 
developing capacities (e.g., childhood) or diminished ones (e.g., intellectual and cognitive impairments) are the two most commonly used examples. Or it might be the case that such self-rule is temporarily absent because, to extend the political analogy, the sovereign is currently being held hostage by terrorists and forced to accede to their irrational demands.

\section{Ulysses contracts and conceptions of addiction}

As we have seen, Ulysses contracts exhibit a preoccupation with the idea of a temporary subversion of one's 'true' or 'authentic' self-whether the source be a manic episode in the context of a person with a mental disorder or the compulsion of a drug user in recovery to use again. They thus speak to contemporary understandings of both the nature of mental illness and addiction - and the paradigmatic connection drawn between them. Indeed, the expansion of Ulysses contracts from mental health to addictions treatment is itself telling, and speaks to the tendency to collapse 'mental health' and 'addiction' in health policy and programming and clinical practice. ${ }^{9}$ It also illustrates the ways in which notions of madness established in the nineteenth century essentially became the basis for articulating a larger medical model of deviance (Foucault 1965; Szasz 1970, 1973; Levine 1978). However, as Mariana Valverde (1998) observes, the analogy only goes so far - a fact that becomes apparent in legal contexts, where insanity is a viable defense for criminal behavior but addiction rarely is. ${ }^{10}$ In her words, "If popular culture is at ease with the idea that the self is not always unified, expert knowledges, by contrast, generally wish to confine such phenomena to the realm of insanity" (p. 191).

This sense of unease is evident in the legal response to a class action suit against the Ontario Lottery and Gaming (OLG) Corporation initiated in 2009 by more than ten thousand self-professed problem gamblers, all of whom had voluntarily signed a type of Ulysses contract known as a 'self-exclusion contract'11 to bar their entry to any casinos or gambling venues (Priest 2009; see Buchman 2009 for an analysis). According to Peter Dennis, the plaintiff at the center of the class action suit, "I could not stop myself from the gambling... It consumed me." After gambling \$500,000 between 2001-2004, on 24 May 2004 he entered an OLG venue, said he had a serious gambling problem, and asked to sign a self-exclusion form. A security guard then photographed him and told him that he could be charged with trespassing if he entered any of the OLG's casinos or gambling venues. However, Dennis was able to enter a gambling venue unimpeded the following week - and for the next three years.

\footnotetext{
${ }^{9}$ After all, the Diagnostic and Statistical Manual of Mental Disorders (more commonly known as the DSM) includes 'substance use and addictive disorders' as one of its categories.

${ }^{10}$ As Valverde (1998, p. 195) notes, it is often likely to aggravate rather than mitigate sentencing.

${ }^{11}$ Self-exclusion contracts were first implemented by the Société des casinos du Québec, although they have been embraced by many casinos and lotteries as an expression of their commitment to "responsible gambling". However, as the OLG case illustrates, these kinds of contracts are ones in which the ties binding the contractee to the mast are largely self-enforced. For example, Loto-Québec makes it clear that it "assumes no responsibility if the applicant violates the rules of self-exclusion to which he or she voluntarily committed” (Loto-Québec 2014).
} 
The crux of the lawsuit was that the OLG Corporation had neglected their responsibility to act on these self-exclusion contracts and bar the problem gamblers from their premises. In 2010, an Ontario Superior Court judge, Justice Cullity, ruled against the class action suit proceeding. ${ }^{12}$ In his ruling he argued that while compulsive gamblers might be considered "vulnerable", it was impossible to ascertain whether all the class members were, in fact, "pathological problem gamblers" (Cullity 2010). In his view, "a consideration of the nature, degree and consequences of each class member's gambling propensities" was required (Cullity 2010). In other words, the signing of the Ulysses contract was not, in itself, proof of a compulsive gambling addiction that overrode the plaintiffs' sense (and self).

Although the subject of some legal suspicion, this notion of compulsion is central to contemporary articulations of addiction (Levine 1978; Valverde 1998; Weinberg 2002; Keane 2002; Room 2003; Seear and Fraser 2010; Levy 2013), with addiction characterized as a kind of "slavery from within" (Valverde 1998, p. 5). As Robin Room (2003) observes, central to the cultural framing of addiction is the notion that drug use causes certain behavior that would not otherwise occur. Going further, he argues that addiction is conceptualized as a "secularized and rationalized form of ideas about possession" (p. 226) wherein the person's being is understood to be usurped by a force that takes control of the person's behavior against his or her will.

This conceptualization of addiction is illustrated to good effect in an episode of Radiolab, a show on National Public Radio in the USA (Radiolab 2011). The segment, titled "You v. you", was devoted to the topic of Ulysses contracts and focused primarily on Zelda, an 80 -year-old woman who smoked for 30 years. In the segment, Zelda recounts her shift from smoking casually to "getting hooked" to how she eventually kicked the habit. Highlighting her endless process of quitting and relapsing, Zelda emphasizes that everything changed on one particular day in 1984 when she made a deal with her friend Mary that if she ever smoked again she would give \$5,000 to the Ku Klux Klan. Interspersed with the lead-up to Zelda's revelations about her "Ulysses pact" are segments of an interview with Thomas Schelling (cited earlier) in which he discusses precommitment contracts, or, in his words, "arranging it so you can't compromise".

The interviewer and Zelda then have the following exchange:

Zelda: \$5,000 to the Klu Klux Klan. It just came out of my mouth. You know how horrible they are, right?

Interviewer: Sure.

Zelda: So heinous.

Interviewer [in voiceover]: But her and Mary made a deal.

Mary: - a pact.

Interviewer [in voiceover]: If Zelda smoked, she'd have to tell Mary to send the KKK her money.

\footnotetext{
${ }^{12}$ In 2012 the Ontario Court of Appeal gave the plaintiffs leave to appeal the decision (Brown 2012).
} 
Zelda: - Take it out of my savings or something.

Interviewer: And you were really serious? You were gonna do this?

Zelda: Yeah, but I have to say, after I made this pledge to Mary, under my breath

I said, "But I can't be responsible if she smokes again".

Interviewer: What? If she smokes again?

Zelda: if she smokes again.

Interviewer: Who's the 'she' in that sentence?

Zelda: Me.

Interviewer: You. What does that mean?

Zelda: Well, that means that a part of me - the part of me that was smoking and

that might pick up smoking again — was an alien part.

Interviewer: You're saying you were two people at that moment?

Zelda: Yeah.

Interviewer: And she-

Zelda: - 'Z', didn't really want to stop smoking.

Interviewer: She.

Zelda: She. Yeah.

Via further discussion with Schelling and an interview with a neuroscientist, the segment goes on to detail the existence of these different selves that live inside each of us; "there are different parts of the brain that are battling this out" the neuroscientist declares. The segment presents the Ulysses pact as the solution to this problem because these different selves are forced to confront each other.

Drawing on Harry Levine's (1978) important work on the 'discovery' of addiction, Room argues that these ideas about addiction as a kind of secularized possession are the product of a specific cultural and historical logic. As Levine (1978) documents, in the colonial era, drunkenness was perceived to be due to an excess love of drink, instead of an overwhelming compulsion to drink despite one's own intentions. According to Levine, this difference is subtle but important insofar as notions of the contemporary self rely on an opposition between 'desire' and 'will', whereas earlier notions of will and desire treated them as identical, not opposed. Although De Quincey's Confessions of an English Opium Eater was written well after the 'disease of the will' model of addiction had come to prominence, the tensions between the older and newer frameworks are evident to some degree in De Quincey's account of Coleridge's Ulysses contract with his porter. In De Quincey's words: "such a vassalage must have been created willfully and consciously by his [Coleridge's] own craving after genial stimulation... For my own part, I laid aside the opium, not under any meritorious effort of self-conquest; nothing of that sort do I pretend to do" (p. 607).

Nevertheless, this notion of the "diseased will" (Valverde 1998), and the split between will and desire on which it is premised, is deeply entrenched in contemporary models of addiction. In many respects, it has achieved a new force with the rise of neuroscientific models of addiction, although Rose (2003: 407) observes that addiction is increasingly seen not as a "disease of the will" but a "disease of the brain". Neurobiological accounts of addiction emphasize the ways in which chronic drug use creates neurocognitive 
changes in the brain that impair users' voluntary control over their behavior (Carter, Hall and Illes 2012). In such framings, neurotransmitters and the new neural circuits and pathways they inscribe become the equivalent of the Sirens' song ${ }^{13}$ — creating an irresistible pull that sways 'addicts' to act against their intentions to stay clean.

This differentiation between will and desire - and its instantiation in neuroscientific models of addiction - is at the root of the colonizing tendencies of the concept of addiction and its endless expansion into more and more realms. As Eve Kosofsky Sedgwick (1993) has argued, today every form of human behavior is brought into the orbit of potential addiction attribution, from sex to eating to exercise to, potentially, the desire for self-improvement itself: "Understood logically, the circumference of addiction attribution is nowhere to be drawn" (p. 131). For Sedgwick, this is because addiction is understood to reside in the structure of a will that is always insufficiently free - a choice whose voluntarity is insufficiently pure. Under such a conception, the healthy free will is the abstract space where substances and behaviors become 'addictive' or 'not addictive'.

Sedgwick argues that this hypostatized notion of 'free will' relies on an equally reified notion of 'compulsion' that is both internal to it but simultaneously requiring ejection from it. The end result is the invention of a Will whose potency and value seem to become ever more absolute as every grounding possibility for its coming into existence recedes further away. In her words:

The demand for its [the Will's] propagation seems to require, however, not only that it spread and circulate but that it be continually displaced: even, that the concept of free will withdraw eternally across a network of contingencies to constitute, at the last, a horizon of absence whose pressure on what is present then approaches the absolute (Sedgwick 1993: 132).

The contradictions Sedgwick identifies in this notion of 'free will' crystallize in arguments endorsing forced treatment on the basis of "denying autonomy in order to create it" (Caplan 2008, p. 1919). Thus, Arthur Caplan (2008) argues that coerced treatment for addiction paradoxically serves to rebirth autonomy. In his words,

If naltrexone ${ }^{14}$ or any other drug can permit people to make choices freed from the compulsions or cravings that would otherwise control their behavior completely, then it would seem morally sound to permit someone who is in the throes of addiction to regain the ability to choose, to be self-governing, even if the only way to accomplish this restoration is through a course of mandated treatment (Caplan 2008: 1919, emphasis added).

Similarly, Jannssens et al. (2004) assert that to respect the patient:

\footnotetext{
${ }^{13} \mathrm{I}$ am indebted to one of the $C M P$ reviewers for this insight.

${ }^{14}$ See Keane (2002, p. 13) for further discussion of the perceived power of naltrexone to 'restore' people to their 'natural' state; as she notes, in such accounts, heroin is attributed the "preternatural power of possession". Here, naltrexone in effect becomes the tie the binds users to the mast, enabling them to resist the Siren call of drugs.
} 
Sometimes this implies that the current preferences of the patient are overruled in favour of other, longer term goals and values. In this sense, the autonomy of the patient is safeguarded, not by upholding his right to nonintervention but, contrarily, by intervention (Janssens et al. 2004: 457).

These arguments largely duplicate the earlier endorsements of the forced treatment of people with mental health issues that Szasz railed against, where it was argued that: "commitment can be justified on the grounds of enhancing the individual's future freedom" (Peele and Keisling in Szasz 1982, p. 765). Noting the contradiction inherent in "depriving persons of liberty in a mental hospital in order, ostensibly, to 'liberate' them" (p. 765), Szasz saw this as an example of the excesses of "psychiatric protectionists". However, in my view, these kinds of arguments are not so easily brushed aside as perversions of the notions of freedom and choice. Instead, I suspect that they may actually be the logical (perhaps even inevitable) outcome of the "propaganda of free will" (Sedgwick 1993, p. 132). Here, the Will is revealed as a Möbius strip ${ }^{15}$ where the dual surfaces of freedom and coercion collapse into each other. However, instead of disrupting this apotheosized free will, such accounts conversely serve to facilitate its "direct and inexorable continuation" (Sedgwick 1993, p. 132). The concept of the Ulysses contract has a critical role to play in stabilizing this version of the will (otherwise in clear danger of being exposed as a fiction), because of the ways it reconciles absolute compulsion and absolute voluntarity. After all, under its logic, phrases like "voluntary involuntary treatment" (Rosenson and Kasten 1991, p. 1) are no longer oxymorons but desirable outcomes.

\section{Conclusion}

In this paper I have explored the emergence of Ulysses contracts in the treatment of mental illness and addiction. As I have emphasized, the formal use of these contracts to pre-emptively commit 'addicts' to treatment is not common, primarily because of the barrage of legal, practical and ethical issues they raise. However, examples of informal, self-imposed Ulysses contracts are widely available - whether the context be opiate addiction, quitting smoking or even 'problem' gambling. Although such contracts are arguably somewhat different from pre-emptively agreeing to treatment in the event that one falls back into drug use, they are nevertheless each based on similar assumptions about the nature of addiction and the self. Premised on the assumption of an 'authentic' self jeopardized by a usurping alien force (writ as impulsive, compulsive, irrational, insane, self-destructive, and so on), such contracts seek to reassert its sovereignty by binding the alien self to its Will. In so doing, the abdication of 'the will' thus becomes the key to exerting it.

\footnotetext{
${ }^{15}$ The Möbius strip, immortalized in the work of M.C. Escher (see http://www.mcescher.com/gallery/recognition-success/mobius-strip-ii/), is an object that looks to have two surfaces, but is ultimately revealed to have only one side and boundary component.
} 


\section{References}

Andreou, Chrisoula

2008 Making a Clean Break: Addiction and Ulysses Contracts. Bioethics 22(1): 25-31.

Beauchamp, Tom L. and James F. Childress

2001 Principles of Biomedical Ethics. Fifth Edition. Oxford: Oxford University Press.

Brown, Jennifer

2012 Appeal Court Grants Leave to Appeal in OLG Class Action. Canadian Lawyer. Electronic document, http://www.canadianlawyermag.com/4280/appeal-court-grants-

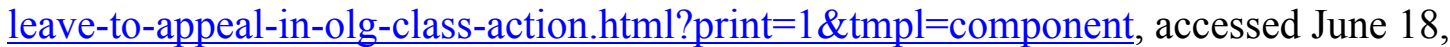
2014.

Buchman, Daniel 2009 Ulysses Contracts and a \$3.5-Billion Gamble. Neuroethics at the Core. Electronic document, http://neuroethicscanada.wordpress.com/2009/04/21/ulysses-contracts-and-a35-billion-gamble/, accessed June 18, 2014.

Caplan, Arthur

2008 Denying Autonomy in Order to Create it: the Paradox of Forcing Treatment on Addicts. Addiction 103: 1919-1921.

Carter, Adrian, Wayne Hall and Judy Illes (eds)

2012 Addiction Neuroethics: the Ethics of Addiction Neuroscience Research and Treatment. London: Academic Press.

Cuca, Roberto

1992 Ulysses in Minnesota: First Steps Toward a Self-Binding Psychiatric Advance Directive Statute. Cornell Law Review 78: 1152-1186.

Cullity, Maurice.

2010 Dennis et al. v. Ontario Lottery and Gaming Corporation. Ontario Superior Court of Justice, 1332 (CanLII). Electronic document, http://canlii.ca/t/2900xm, accessed June $18,2014$.

Culver, Charles M. and Bernard Gert

1981 The Morality of Involuntary Hospitalization. Philosophy and Medicine 9: 159-175.

Davis, John K.

2008 How to Justify Enforcing a Ulysses Contract When Ulysses is Competent to

Refuse. Kennedy Institute of Ethics Journal 18(1): 87-106.

De Quincey, Thomas

1867 Confessions of an English Opium Eater. Boston: Houghton, Mifflin and Company.

Dresser, Rebecca 
1984 Bound to Treatment: the Ulysses Contract. The Hastings Center Report 14(3): 1316.

Elster, Jon

1984 Ulysses and the Sirens: Studies in Rationality and Irrationality. Cambridge:

Cambridge University Press.

2000 Ulysses Unbound: Studies in Rationality, Precommitment, and Constraints. Cambridge: Cambridge University Press.

2007 Explaining Social Behavior: More Nuts and Bolts for the Social Sciences.

Cambridge: Cambridge University Press.

Foucault, Michel

1965 Madness and Civilization: a History of Insanity in the Age of Reason. New York:

Vintage Books.

Frankfurt, Harry G.

1971 Freedom of the Will and the Concept of a Person. Journal of Philosophy 68(1): 520.

Fraser, Suzanne, David Moore and Helen Keane

2014 Habits: Remaking Addiction. London: Palgrave Macmillan.

Green, Donald P. and Ian Shapiro

1994 Pathologies of Rational Choice Theory. New Haven: Yale University Press.

Homer

2005 The Illiad and The Odyssey. Translated by Samuel Butler and edited by James H. Ford. El Paso: El Paso Norte Press.

Howell, Timothy, Ronald J. Diamond and Daniel Wikler

1982 Is There a Case for Voluntary Commitment? In Contemporary Issues in Bioethics. Tom L. Beauchamp and LeRoy Walters, eds. Pp. 163-168. Belmont: Wadsworth.

Janssens, M.J.P.A., M.F.A.M. Van Rooij, H.A.M.J. ten Have, F.A.M. Kortmann and F.C.B. Van Wijmen 2004 Pressure and Coercion in the Care for the Addicted: Ethical Perspectives. Journal of Medical Ethics 30: 453-458.

Keane, Helen

2002 What's Wrong with Addiction? Melbourne: Melbourne University Press.

2003 Critiques of Harm Reduction, Morality and the Promise of Human Rights. International Journal of Drug Policy 14(3): 227-32. 
Levine, Harry G.

1978 The Discovery of Addiction: Changing Conceptions of Habitual Drunkenness in America. Journal of Studies on Alcohol 39: 143-74.

Levy, Neil (ed)

2013 Addiction and Self Control: Perspectives from Philosophy, Psychology, and

Neuroscience. Oxford: Oxford University Press.

Loto-Québec

2014 Responsible gambling. Electronic document,

http://www.casinosduquebec.com/montreal/en/responsible-gambling, accessed

September 27, 2014.

Macklin, Audrey

1987 Bound to Freedom: the Ulysses Contract and the Psychiatric Will. University of

Toronto Law Review 45(1): 37-68.

Mill, John Stuart

1859/2001 On Liberty. Kitchener: Batoche Books.

Moore, David and Suzanne Fraser

2006 Putting at Risk What We Know: Reflecting on the Drug-Using Subject in Harm

Reduction and its Political Implications. Social Science and Medicine 62(12): 3035-47.

National Alliance on Mental Illness

2014 Advance Directives. Electronic document, http://www.nami.org/Content/ContentGroups/Legal/Advance_Directives.htm, accessed May 12, 2014.

O’Malley, Pat and Mariana Valverde

2004 Pleasure, Freedom and Drugs: the Uses of 'Pleasure' in Liberal Governance of

Drug and Alcohol Consumption. Sociology 38(1): 25-42.

O’Neill, O.

1984 Paternalism and Partial Autonomy. Journal of Medical Ethics 10(4): 173-178.

Picard, H. and Pearce, S.

2013 Addiction in Context: Philosophical Lessons From a Personality Disorder clinic. In Addiction and Self-Control: Perspectives from Philosophy, Psychology, and

Neuroscience. Neil Levy, ed. Pp. 165-189. Oxford: Oxford University Press.

Priest, Lisa

2009 The Big Bluff. The Globe and Mail, 18 April. Electronic document, http://v1.theglobeandmail.com/servlet/story/RTGAM.20090418.wgamble18/front/Front/

Front/sympatico-front, accessed June 17, 2014. 
Radden, Jennifer

1982 Choosing to Refuse: Patients Rights and Psychotropic Medication. Bioethics 2(2): 83-102.

Radiolab

2011 You V. You. Radiolab. Audio recording, http://www.radiolab.org/story/117291-

you-v-you/, accessed January 20, 2014.

Rogers, Joseph A. and J. Benedict Centifanti

1991 Beyond 'Self-Paternalism': Response to Rosenson and Kasten. Schizophrenia Bulletin 17(1): 9-14.

Room, Robin

2003 The Cultural Framing of Addiction. Janus Head 6(2): 221-234.

Rose, Nikolas

1998 Inventing Our Selves: Psychology, Power, and Personhood. Cambridge:

Cambridge University Press.

2000 Government and Control. British Journal of Criminology, 40: 321-339.

2003 The Neurochemical Self and its Anomalies. In Risk and Morality. Richard

V. Erickson and Aaron Doyle, eds. Pp. 407-437.

Rosenson, Marilyn K. and Agnes G. Kasten

1991 Another View of Autonomy: Arranging for Consent in Advance. Schizophrenia Bulletin 17(1): 1-7.

Schelling, Thomas C.

1992 Self-Control. In Choice Over Time. George Loewenstein and Jon Elster, eds. Pp.

167-176. New York: Russell Sage Foundation.

Sedgwick, Eve Kosofsky

1993 Epidemics of the Will. In Tendencies. Pp. 129-140. London: Routledge.

Seear, Kate and Suzanne Fraser

2010 Ben Cousins and the 'Double Life': Exploring Citizenship and the Voluntarity/

Compulsivity Binary Through the Experiences of a 'Drug Addicted' Elite Athlete.

Critical Public Health 29(4): 439-452.

Stein, Howard F.

1990 In What Systems Do Alcohol/Chemical Addictions Make Sense? Clinical

ideologies and practices as cultural metaphors. Social Science and Medicine 39(9): 9871000 .

Spellecy, Ryan 
2003 Reviving Ulysses Contracts. Kennedy Institute of Ethics Journal 13(4): 373-392.

Szasz, Thomas S.

1970 The Manufacture of Madness. Syracuse, NY: First Syracuse University Press. 1973 Ideology and Insanity: Essays on the Psychiatric Dehumanization of Man. Middlesex: Pelican Books.

1982 The Psychiatric Will: a New Mechanism for Protecting Persons Against 'Psychosis' and Psychiatry. American Psychologist 37(7): 762-770.

Valverde, Mariana 1998 Diseases of the Will: Alcohol and the Dilemmas of Freedom. Cambridge: Cambridge University Press.

Walker, Tom

2012 Ulysses Contracts in Medicine. Law and Philosophy 31: 77-98.

Weinberg, Darin 2002 On the Embodiment of Addiction. Body and Society 8(4): 1-19.

Winston, Morton E. and Sally M. Winston 1982 Case Studies: Can a Subject Consent to a 'Ulysses contract'? The Hastings Center Report 12(4): 26-28.

Zey, Mary

1998 Rational Choice Theory and Organizational Theory: a Critique. London: Sage. 